\title{
El Estado terrorista y la nuda vida. El caso de la dictadura cívico-militar argentina (1976-1983)
}

Cristina Micieli*

\author{
DOI 10.20399/P1982-999X.2016v1n2pp116-132
}

\begin{abstract}
Resumen
En este artículo analizamos la dictadura cívico-militar argentina (1976-1983) bajo la óptica de la biopolítica y de la ontología derrideana, rastreando las formas en las que la política inaugurada en 1976 y la violencia llevada a cabo se superponen y se enmascaran, y la manera cómo, en su reverso, aparecen las denominadas "figuras de la persecución". El Estado de excepción, bajo la dictadura, dio lugar a un Estado de seguridad. El recurso al estado de excepción/seguridad en tanto Estado vacío de derecho, y la búsqueda de una nueva legalidad para construir una legitimidad que no se poseía son puntos analizados en este artículo. Asimismo, la contigüidad entre FF. AA./golpistas y función de policía tiene como consecuencia la criminalización del adversario. Por su parte, al colocarse por encima de la ley al instituir un estado de excepción, el nuevo soberano asume la figura de la bestia, en la conceptualización de Derrida, la cual también se coloca por fuera de ley al transgredirla.

Palabras-clave: Estado de excepción; Violencia; Nuda Vida; Bestia/Soberanía.
\end{abstract}

\begin{abstract}
This issue analyzes the Argentine military-civic dictatorship (1976-1983) under the scope of biopolitics and Derrida ontology. It searches for ways in which the politics that started in 1976 and the violence carried out are overlapped and hidden, and how there come to appear the so called "pursued people". The State of exception, under dictatorship, gave place to a State of security. This issue also analyses the following topics: a State of exception/security as a State that lacks Law, and the search of a new legality to build a legitimacy that it did not have. On the other hand, contiguity between air forces/coup perpetrators and police function has as a consequence the criminalization of the opponents. The new sovereign people, placing themselves on top of the Law by instituting a State of exception, become a beast according to Derrida concepts, which is also placed outside the Law due to the fact that this beast infringes it.
\end{abstract}

Key-words: State of exception; Violence; Nuda Vida; Beast/Sovereignty.

\section{Introducción}

El tema que nos convoca está cruzado por distintas aristas y perspectivas de estudio. Marina Franco (2012), por ejemplo, se propone relativizar la emergencia de la dictadura militar como un "corte" en la historia, postulando, por el contrario, modos de continuidad entre el período 1973-1976 y el iniciado el 24 de marzo, principalmente en dos aspectos: a) las prácticas estatales represivas, y b) la circulación de determinadas representaciones sociales sobre el problema de la violencia. En tal sentido, la autora se concentra más en el examen de las "continuidades (siempre relativas)" que de las "rupturas (nunca taxativas)".

Percepciones similares en cuanto a la problemática de la continuidad, podemos hallarlas en la obra de Pilar Calveiro (2005), quien observó que en Argentina la admisión de la tortura contra los presos comunes y políticos precedió a 1976, y que el acuerdo sobre la necesidad de exterminar la subversión era ampliamente difundido antes del golpe de estado. En esta misma línea se encuentra el planteo de Hugo Quiroga (2004), al señalar que desde 1930 se organizó en Argentina un sistema político carente

\footnotetext{
* Doctora en Filosofía. Profesora e investigadora de la Facultad de Ciencias Sociales, Universidad de Buenos Aires (UBA); e-mail: cmicieli@educ.ar
} 
de continuidad institucional. En efecto, la presencia del poder militar se convirtió en una constante que coexistía en el interior del sistema político con fuerzas civiles. Ambos, civiles y militares, muchas veces se presentaron como aliados, de ahí su alternancia y la existencia de hecho de dos polos antagónicos: el democrático y el autoritario. Asimismo, cuando los militares intervienen en política es una parte del Estado que lo hace, afirma Quiroga. Por ello, esa actividad extra-militar es lo que les confiere el carácter de fuerza política. No obstante, las FF.AA. actúan de manera "subrepticia", pues niegan su carácter político, lo cual deja de ser encubierto cuando sobreviene un golpe militar.

Por ello, en las lecturas hegemónicas de la época los militares aparecían como víctimas, ya que el "demonio" de la derecha estaba personificado por la Triple A y no por las Fuerzas Armadas (VEZZETTI, 2002). Sin embargo, Calveiro destaca en otra de sus obras (1998) que fueron los militares los primeros en decretar el agotamiento democrático reiterando el mecanismo de hacer desparecer lo inmanejable. Pero el intento de construir una propuesta que ponía el acento en la voluntad de una transformación drástica del presente por parte de las FF.AA. hizo aguas, pues ellas habían sido parte activa de la larga crisis política y estaban impregnadas, por lo tanto, de los mismos factores de desorden y facciosidad que dominaba algunos espacios colectivos (CALVEIRO, 2005).

Así el proceso de construcción de una realidad que legitima la violencia tendría una larga data, y tras la aceptación tácita del proceso de radicalización de 1973, el discurso dominante pasó a ilegitimar la violencia revolucionaria, lo cual amplió los apoyos civiles a las demandas de represión. Por ello, en varios artículos, Alejandro Kaufman (1997) insiste en que hubo una guerra, ya que ésta no se limita a la violencia ejercida sino que se trata de un fenómeno mucho más amplio. Para el ensayista, la existencia de una masa guerrera se conformó en la Argentina en el transcurso de un periodo de varios años.

El argumento de la continuidad encontraría un límite cuando nos preguntamos por las causas específicas y objetivos de un golpe de Estado como el de 1976 que encarceló, incluso, a dirigentes políticos y sindicales que habían formado parte del gobierno de Isabel Perón en sus momentos más represivos. El carácter clasista, antipopulista y antiobrero, y el revanchismo de clase que lo animó (Basualdo, 2002), relativiza la conceptualización del golpe de 1976 en términos de continuidad (LVOVICH, 2012). En esta misma línea, Eduardo Duhalde (1983) da cuenta de que en el periodo tratado no sólo se produce la ocupación del Estado por una fuerza militar sino que, además, se da un cambio cuantitativo y cualitativo de la concepción del Estado mutando su carácter de "público" al de "clandestino" a través del terror como instrumento y método.

La emergencia de la dictadura militar tuvo como principal objetivo destruir un régimen social de acumulación (BASUALDO, 1987, 2002), punto fundamental que da cuenta de una "ruptura" con el período precedente. El plan Martínez de Hoz se propuso refundar estructuralmente la sociedad argentina en términos económico-sociales y políticos, consolidando un nuevo proyecto dominante (SCHVARZER, 1987; ASPIAZU et al, 1986) que precisaba, en una primera etapa al menos, de un enorme poder represivo para agredir una estructura social constituida a lo largo de décadas. Había que remover las bases del modelo distribucionista y no bastaba ya con proscribir al peronismo o atacar a la vanguardia obrera: había que privar tanto al populismo como al movimiento obrero organizado de la base material en que se asentaban (VILLARREAL, 1985). Por ello la denuncia de supuestos "terroristas" fue una forma eficaz de resolver problemas gremiales, sostienen Marcos Novaro y Vicente Palermo (2003). 
Si bien compartimos en términos generales los puntos de vista de los autores citados, nuestro interés se centra sobre todo en analizar esos años bajo la óptica de la biopolítica (AGAMBEN, 2003, 2005, 2013; ESPOSITO, 2004, 2005, 2010) y de la ontología derrideana $(1995,2010)$. Nos interesa pensar la relación que existe entre el "golpe de estado" y la economía de la violencia, que aquél pone en marcha. Es decir, rastrearemos las formas en las que la política inaugurada en 1976 y la violencia llevada a cabo se superponen y se enmascaran, y la manera cómo, en su reverso, aparecen las denominadas "figuras de la persecución". El Estado de excepción, bajo la dictadura, dio lugar a un Estado de seguridad.

El recurso al estado de excepción/seguridad en tanto Estado vacío de derecho, y la búsqueda de una nueva legalidad para construir una legitimidad que no se poseía son puntos a analizar en este artículo. Por su parte, el campo de concentración -presente tanto en el régimen nazi como en la dictadura de 1976- aparece como el espacio político donde el estado de excepción se convierte en regla (AGAMBEN, 2005; MICIELI, 2010).

Esta contigüidad entre FF. AA./golpistas y función de policía tiene como consecuencia la criminalización del adversario. Como señala Agamben, el enemigo puede ser aniquilado a través de una "operación de policía", pero por ello esta criminalización del enemigo se puede convertir en criminalidad del golpista. En efecto, éste muestra su originaria proximidad con el supuesto criminal que busca aniquilar.

Asimismo, al colocarse por encima de la ley al instituir un estado de excepción, el nuevo soberano asume la figura de la bestia, afirma Jacques Derrida (2010), la cual también se coloca por fuera de ley al transgredirla. En consecuencia, el comportamiento bestial del soberano y sus actos criminales no son considerados ilegales.

En tal sentido, categorías como estado de excepción, nuda vida, homo sacer, campo de concentración, tanatopolítica, guerra preventiva, comunidad/inmunidad, y conceptos derrideanos tales como espectro, fuera-de-la-ley, fuerza-de-ley, bestialidad y soberanía política, entre otros, nos parecen de suma importancia.

\section{Luego del tercer peronismo}

Las tradiciones determinan la exclusión comunitaria de ciertos individuos que "profanan" el entorno en el que se desplazan. Cuerpo, color de piel, elección sexual, creencia, orientación política, nacionalidad, etnia $\mathrm{o}$ condición social son desencadenantes de exclusiones. Saturar los prejuicios en determinados sectores sociales y tener piedra libre para agraviarlos no es privativo de Occidente. Cada época y cada lugar codifica a sus parias.

Parecería que el peronismo/populismo (SALAS, 1994) ${ }^{1}$, como el fantasma derrideano cuando se refiere a los espectros de Marx (DERRIDA, 1995), acecha a la Argentina desde 1945. En efecto, el rasgo sobresaliente de lo fantasmático es el asedio, es decir el doble carácter de presente-ausente y de ausente-presente. La figura del espectro pone al descubierto la intrincada relación entre la identidad y la alteridad. Con respecto a la identidad, interfiere en su constitución, impidiéndole adecuarse totalmente a sí misma. Se trata de una especie de visita desde un pasado no del todo realizado o

\footnotetext{
${ }^{1}$ En concordancia con Ernesto Salas, la identidad resistente del peronismo y el recuerdo colectivo tendieron a gestar el mayor enfrentamiento clasista de la Argentina moderna; aun dentro del marco del sistema el peronismo tendió permanentemente a salirse de él. Un imaginario colectivo plagado de tradicionalismo, pero inconciliable por los reclamos obreros, se convirtió en un movimiento dinámico y contradictorio que se opuso a la hegemonía de la clase dominante, gestando en su seno contradicciones insolubles que estallarían a partir de 1973.
} 
desde un porvenir inminente, desincronizando toda contemporaneidad con su propio presente; lo habita sin hospedarse en él, como presencia-ausente que pone en riesgo su propia "entidad" (VERGALITO, 2005, p. 19-24).

El peronismo es como una alteridad fantasmática que asedia una supuesta identidad nacional constituida. Pero yendo más allá, la identidad de la Argentina como Nación desde sus inicios independentistas se halla dislocada, diferida, contaminada por la otredad. Pensemos en el indio, en el negro, en el inmigrante, y más recientemente, en el cabecita negra.

Las dictaduras sucesivas no pudieron conjurar esta presencia de lo ajeno en lo supuestamente propio. "Lo plebeyo" se hace presente y contamina "lo civilizado", interfiriendo en él. El homo sacer ${ }^{2}$, aquél hombre rastreado por la arqueología de Agamben que puede ser asesinado sin que ello constituya en sí mismo un homicidio, vuelve a irrumpir en la historia reciente bajo la figura del "subversivo"3.

Al respecto, Videla (2013) reveló con claridad que el golpe de Estado no se debió tanto a la lucha contra las guerrillas sino a una razón más abarcadora: "Nuestro objetivo era disciplinar a una sociedad anarquizada, volverla a sus principios, a sus cauces naturales. Con respecto al peronismo, salir de una visión populista, demagógica, que impregnaba a varios sectores; con relación a la economía, ir a una economía de mercado, liberal. Un nuevo modelo, un cambio bastante radical; a la sociedad había que disciplinarla para que fuera más eficiente. Queríamos también disciplinar al sindicalismo y al capitalismo prebendario" (REATO, 2012).

La realidad argentina era tratada como si estuviera afectada de un mal radical antropológica, psicológica y filosóficamente. El nombre de este mal que aquejaba a la nación, y del cual los argentinos eran responsables tiene un nombre: peronismo. A partir del 24 de marzo de 1976, la política de desapariciones de la organización parapolicial Triple A (Alianza Anticomunista Argentina) del gobierno anterior (1973-1976) tomó el carácter de modalidad represiva estatal, abriendo una nueva época en la lucha contrainsurgente. En pocos meses, las FF.AA. destruyeron casi totalmente al Ejército Revolucionario del Pueblo (ERP) y a las regionales de Montoneros. La dictadura dará los golpes finales sobre fuerzas política y militarmente diezmadas, y a través del terrorismo de Estado, extenderá con inusitada crueldad una represión buscando el redisciplinamiento social.

\footnotetext{
${ }^{2}$ Según el derecho romano arcaico homo sacer es un individuo juzgado por el pueblo como autor de un delito, que lo convierte en un ser marcado, un ser no sacrificable a los dioses (como sí se puede hacer con un ser puro). Quien mate al que la comunidad declaró sagrado no será condenado por homicidio. En esta situación particular, el término sacer parece negar lo que afirma, pues al mismo tiempo que otorga la sacralidad a una persona, establece la prohibición de inmolarla en un altar. Pero se la puede asesinar sin pagar por ello, porque la ley autoriza a que se le dé muerte impunemente. Mientras está prohibido violar cualquier cosa o persona sagrada -declarada como tal mediante ritos sacerdotales- es lícito matar a quien pasó a ser sagrado a partir del juicio de la sociedad (o en nuestro caso de una parte de ella). Quien responde a la categoría de homo sacer por designio del pueblo pasa a ser posesión de los dioses infernales. En ese sentido, se lo ha expulsado del orden humano, por lo tanto no representa delito quitarle la vida. Jurídicamente es matable y socialmente descartable. La violencia que se le infrinja al individuo sagrado no representa sacrilegio ni crimen. Ha perdido su plenitud humana, es "mera vida". Una vida que no está atravesada por connotaciones jurídicas ni políticas. La persona sagrada (en el sentido aquí establecido) es aquella respecto de la cual todos los humanos pueden actuar como soberanos. Su vida está expuesta a la exclusión y a que se le dé muerte impunemente.

${ }^{3}$ A partir del siglo XIV, la palabra subversión comenzó a ser utilizada en la lengua inglesa en referencia a temas del ámbito jurídico y, un siglo más tarde, empezó a emplearse con relación a las monarquías. Poco a poco, la palabra subversión comenzó a adquirir su significado actual, que se refiere a los intentos de socavar los cimientos de un sistema de poder, como el Estado. De esta manera se puede determinar que todas aquellas acciones tales como un golpe de Estado son una subversión, una forma de intentar destruir al régimen, monarquía o gobierno republicano en un lugar concreto.
} 


\section{La lógica de la soberanía y la economía de la violencia}

El golpe de Estado del 24 de marzo de 1976 instaló una nueva soberanía que, en la óptica de Giorgio Agamben (2005a), inauguró una nueva legalidad a través de un Estado de excepción. Bajo esta lógica gobierna lo negativo sobre lo positivo, sea para definirlo, como en el caso de la relación enemigo/amigo, sea como preeminencia en la perspectiva ontológica entre la muerte y la vida. La decisión soberana se apoya en la negación de lo que quiere establecer o proteger: decidiendo sobre el enemigo público se establece la identidad y unidad de la comunidad (de amigos); gracias al poder de decidir (excepcionalmente) sobre la muerte es posible el momento soberano que, al no dar muerte, permite la vida.

El lenguaje de la dictadura incurrió en una vaguedad deliberada y feroz cuando acuñó el concepto de "subversión". La palabra subversión a secas se refería a todo aquél que atentara contra el "estilo de vida argentino" o el "ser nacional", ambos indefinibles y, por consiguiente, absolutos. "Una de las características del terrorismo de Estado es la a-tipificación del delito...Serán culpables los que el Estado decida que lo son y por las razones que el Estado decida" (FEINMANN, 2004). La connotación del término "subversivo" es lo suficientemente difusa como para atribuir el rasgo de enemigo a todo aquél que no fuera idéntico. "Estamos dentro de la prisión del Uno. Pero lo Uno, antes de constituirse como Poder, se origina en la potencia simbólica encapsulada de la lógica de la identidad" (MARRAMAO, 2013, p. 62).

Como vemos, bajo la lógica de la soberanía, en tanto espacio de la decisión determinante de la excepción, se puede observar que para asegurar el derecho e instaurar una comunidad política con determinadas características, opera una economía de la violencia que lleva a cabo una gestión diferenciada de la vida. La violencia se enmarca en instituciones político-jurídicas para proteger la comunidad delimitándose su identidad a partir del establecimiento de su afuera, instaurando el lugar paradójico de lo fuera-de-la-ley, instancia que comparten la figura del soberano con su reverso: las figuras de la persecución (TORRANO; LORIO, 2012).

Desde el comienzo, y aún antes del orden autoritario, los enemigos fueron identificados como subversivos, populistas, estatistas, corruptos e indecisos. Las FF. AA. impusieron un orden que puso en escena la lógica poderosa del dar muerte. Para el "Proceso" los subversivos quedaban afuera de la categoría de "persona"4, como si se tratara de seres distintos a ese argentino "puro" que debía ser "protegido". Se niegan vidas para proteger vidas; esta es la paradoja de la tanatopolítica. La inmunidad preserva la comunidad, afirma Esposito (2010). Cualquier "contagio" del cuerpo social habrá de conjurarse con la guerra preventiva. Dicha lógica se arroga la facultad de interpretar los miedos ante lo "extraño", así como la necesidad de protección ante peligros reales o aparentes.

La tanatopolítica, según Agamben (2003), no se efectiviza sobre cualquier vida. En este sentido, para que opere la muerte es necesario que intervenga una cesura, un desgarro en el interior de lo social que indique que una determinada vida no merece ser vivida, que hay algo menos que humano en la propia humanidad. Para explicar tal categoría, el filósofo italiano nos presenta un nuevo concepto: nuda vida. Como resultado de un minucioso procedimiento biopolítico, la vida es despojada de su forma (humana), quedando "desnuda".

\footnotetext{
4 "No desaparecieron personas, sino subversivos", declaración del Jefe de Policía de la Provincia de Buenos Aires durante la dictadura, general de brigada Ramón Camps.
} 


\section{Hacia un nuevo estado de excepción}

"Vivíamos unos tiempos turbulentos y había que dar una respuesta. Ítalo Luder 5 llegó a firmar los decretos para que las Fuerzas Armadas del país pudieran actuar efectivamente en la lucha contra los 'subversivos' y el terrorismo. También se decidió que las fuerzas de seguridad del Estado, conjuntamente con las Fuerzas Armadas, se coordinasen en estas acciones antiterroristas...El acuerdo se firmaba para combatir el terrorismo en todas sus formas y hasta el aniquilamiento definitivo;... más tarde, cuando fuimos juzgados, se le preguntó a Luder por el término aniquilar e hizo una excelente exposición en términos semánticos sobre la cuestión, que se resume en reducir a la nada; no tiene otra interpretación. A partir de ese momento, de hecho y de derecho el país entra en una guerra, pues no salimos como Fuerzas Armadas a cazar pajaritos, sino a combatir al terrorismo y a los subversivos" (El subrayado es nuestro). Tales las palabras de Videla en una entrevista concedida a Cambio 16 en marzo de 2013, no obstante cabe señalar que la planificación del golpe había sido meticulosa, nada había sido sometido al azar, así lo muestran los diversos Documentos editados por el "Proceso" (1976, 1977, 1980, 1983).

Ya en el primer día la Junta Militar dictó 31 comunicados. El comunicado $\mathrm{N}^{\circ} 1$ afirmaba que el país se encontraba bajo el control operacional de la Junta de Comandantes Generales de las FF.AA., recomendándose el estricto acatamiento a las disposiciones y directivas que emanen de autoridad militar. De acuerdo con el comunicado $\mathrm{N}^{\mathrm{o}} 19$, se reprimiría con la pena de reclusión por tiempo indeterminado el que difundiera comunicados o imágenes atribuidas a asociaciones ilícitas o a personas o grupos dedicados a "actividades subversivas o al terrorismo". Asimismo, se impusieron la pena de muerte y los Consejos de Guerra (Ley 21.264).

Así, en la Argentina del tercer peronismo (1973-1976), el estado de excepción como lo considera Agamben (2005a) - se preparaba en las sombras, irrumpiendo con toda su fuerza en 1976.

Hagamos previamente un rodeo teórico. Según Schmitt, la esencia de la soberanía del Estado no estriba en la coacción sino en asumir "el monopolio de la última decisión" (1998, p. 35), donde la autoridad para crear derecho no necesita tenerlo. Surge así el problema de la legitimidad del Estado para la decisión última sobre el derecho. Estas dos características, excepcionalidad y decisión, constituirían las competencias exclusivas del soberano.

Mientras que Schmitt intenta resolver la tensión entre legitimidad y legalidad en la decisión del soberano, para concluir que éste tiene la legitimidad para restituir o instituir un ordenamiento jurídico, para Agamben legitimidad y legalidad permanecen dislocadas: la legalidad no puede adquirir jamás legitimidad. Agamben sigue, en este punto, la distinción derridiana entre "fuerza-de-ley" y ley, esto es, entre los actos que no son leyes pero tienen fuerza-de-ley, o sea, capacidad de obligar. En este sentido, "el estado de excepción es un espacio anómico en el que se pone en juego una fuerza-de-ley sin ley (que debería escribirse, por lo tanto: fuerza-de-ley)" (2005a, p. 81). En el estado de excepción, la decisión del soberano suspende la ley pero no su fuerza, es una fuerzade-ley. El estado de excepción sería, en consecuencia, un espacio vacío de derecho.

En efecto, para gobernar la dictadura inventó su propia legalidad, creyendo que con ello adquiriría legitimidad, desconociendo la Constitución, el Parlamento y las

\footnotetext{
${ }^{5}$ Quien en su calidad de Presidente de la Nación, en 1975, mientras Isabel Martínez de Perón estuvo de licencia y quien firmó los famosos decretos 2770/1/2 a los que se refiere Videla. Más allá de ello, Luder en distintas declaraciones dirá que "aniquilamiento" de ninguna manera significaba "aniquilamiento físico ni violación de la estructura legal”.
} 
normativas del Estado democrático. La Junta de Comandantes creó el Acta y el Estatuto de lo que se llamará "Proceso de Reorganización Nacional", a los que se sometieron todas las otras leyes, incluida la Constitución vigente, imponiendo una serie de "principios liminares" y "objetivos básicos".

Las principales normas supraconstitucionales establecidas fueron las siguientes: Reglamento para el funcionamiento de la Junta Militar, Poder Ejecutivo y Comisión de Asesoramiento Legislativo (aprobado por la "ley" 21.256, del 24-3-1976); Acta para el Proceso de Reorganización Nacional (del 24-3-1976); Estatuto para el Proceso de Reorganización Nacional (publicado el 29-3-1976); Acta fijando el Propósito y los Objetivos Básicos del Proceso de Reorganización Nacional (31-3-1976).

En este marco, la organización jurídica del régimen militar instalado en 1976 acarrea una serie de enormes modificaciones del estado de derecho, que ya venía sufriendo cambios desde gobiernos anteriores. En este punto, vemos con claridad la génesis de un nuevo derecho. Remitiéndose a Walter Benjamin (1991), Roberto Esposito advierte que el derecho no es la abolición del antiguo ritual del sacrifico de una víctima sino su transposición moderna. La violencia en lugar de ser eliminada es asumida por el poder. Siguiendo la argumentación de Benjamin, observa que la "dialéctica inmunitaria" que se determina de este modo se puede resumir en tres pasos conectados entre sí: al comienzo hay siempre un acto violento -una guerra o una usurpación como en el caso que nos ocupa- que funda un orden jurídico. Después, una vez fundado, el derecho tiende a excluir cualquier otra violencia externa a sus procedimientos. Pero sólo puede hacerlo violentamente, haciendo uso de la violencia que condena (ESPOSITO, 2010, p. 15). El estado de excepción es esencialmente un espacio vacío, en el que una acción humana sin relación con el derecho tiene frente a sí una norma sin relación con la vida.

El lugar donde se puede observar con mayor claridad la articulación entre derecho y violencia, características del soberano, es la policía, pues ésta actúa en el estado de excepción decidiendo sobre el "orden público" y la "seguridad". En este sentido, la policía se mueve, al igual que el soberano, en una zona de indistinción entre violencia y derecho. Pero en el caso de Argentina, al llevarse a cabo un golpe de Estado que destituye al "soberano", el lugar de policía es sustituido por las FF. AA. en forma directa, sin artilugios ni enmascaramientos; FF AA. que dependen de sus propios mandos superiores, lo mismo que las otras fuerzas de seguridad. Son el nuevo soberano y en la toma de decisiones últimas parece no haber vestigio de civilidad 6 .

Esta contigüidad entre FF. AA./golpistas y función de policía tiene como consecuencia la criminalización del adversario. Como señala Agamben, el enemigo puede ser aniquilado a través de una "operación de policía" (2005a, p. 31), pero, por ello, esta criminalización del enemigo se puede convertir en criminalidad del golpista. En efecto, éste muestra su originaria proximidad con el supuesto criminal que busca aniquilar.

Así, el estado de excepción se sitúa fuera del orden jurídico normal, pero no es meramente un espacio exterior, ya que lo que en él se excluye es, según el significado etimológico del término excepción, sacado fuera, incluido por medio de su propia exclusión. En consecuencia, lo que de esta forma queda incorporado es el estado de excepción mismo, estado en el que la norma se hace indiscernible de la excepción. El estado de excepción es un híbrido de derecho y de hecho, por lo cual carece de sentido

\footnotetext{
${ }^{6}$ Con esta afirmación no queremos reducir exclusivamente a un carácter militar a la dictadura de 1976, ya que sin apoyos civiles no hubiera podido concretarse. Más aún, pensamos que el "Proceso de Reorganización Nacional" llevó a cabo un nuevo modelo socio-económico concomitante con los intereses de los grandes grupos económicos (BASUALDO, 2006).
} 
cualquier pregunta sobre la legalidad o ilegalidad de lo que en él sucede. De aquí en más, cualquier acción que se lleve a cabo contra los seres humanos no será considerada delito por parte de los nuevos detentadores de la soberanía (AGAMBEN, 2005a, p. 31; $2015)^{7}$.

Una opinión recurrente ubica como fundamento del estado de excepción a la "necesidad", por la que se justificaría la interrupción del curso institucional para salvar el destino de la Nación que se ha desviado de un rumbo predeterminado. Tal desvío, en este caso, sería obra de Isabel Perón, quien se ha colocado fuera de la ley pues ha traicionado el mandato constitucional. El golpe de Estado aparece como una necesidad de salvaguarda de la Patria y de su "destino de grandeza".

El estado de excepción como figura de la necesidad se presentaba como una disposición ilegal pero "jurídica y constitucional", y se concretaba en la producción de nuevas normas. Sin embargo, la teoría de la necesidad lejos de presentarse como un dato objetivo, implica un juicio subjetivo. En tal sentido, son necesarias y excepcionales aquellas circunstancias que son declaradas como tales. El concepto de necesidad es totalmente subjetivo y se relaciona con el objetivo que se quiere alcanzar. En algunos casos, por "necesidad" se han dictado nuevas normas pues se considera que de lo contrario el orden jurídico vigente se vería amenazado. En este ejemplo, el orden existente debe ser conservado.

En otros, se proclama que por "necesidad" se promulga una nueva norma para anular instituciones vigentes. Según Agamben, en uno y otro caso, el recurso a la "necesidad" implica una valoración moral y política -extrajurídica- por la cual puede juzgarse que el orden vigente es digno de conservación o bien que puede ser violado (2005a, p. 68).

El intento de resolver el estado de excepción en el estado de necesidad choca, de este modo, con graves aporías, más de las que las que presentaba el fenómeno que habría debido explicar. "No sólo la necesidad se reduce en última instancia a una decisión, sino que aquello sobre lo cual ella decide es, en verdad, un indecible de hecho y de derecho" (Agamben, 2005a, p. 68).

Los "procesistas" han interpretado como necesario el derrocamiento de Isabel Perón ante la supuesta situación objetiva de vacío de poder y al alto grado de conflictividad social. En tal caso, para poder revertir la situación era necesario hacerse con la totalidad de los resortes del poder, y concretamente, con el del Estado, para contar con los instrumentos necesarios para enfrentar la situación.

Como dijimos, los actos y normas de la Junta Militar tenían prioridad y estaban por encima de la Constitución; el artículo 14 del Estatuto lo determinaba en estos términos. Además, al atribuirse esta potestad, la Junta se asignaba poderes ilimitados: así en nombre de las FF.AA., invocando un "estado de necesidad", se apropiaba del poder constituyente, sometiendo a su voluntad a todos los demás poderes. "El status necessitatis se presenta como una zona ambigua e incierta" (AGAMBEN, 2005a, p. 66) en la cual los procedimientos de facto, en sí mismos extra o antijurídicos, pasan a ser de derecho, y las normas jurídicas se indeterminan en mero facto. Hecho y derecho se vuelven indecibles.

El Estado de excepción, bajo la dictadura, dio lugar a un Estado de seguridad, el cual presenta tres características: el mantenimiento de un estado de miedo generalizado, la despolitización de los ciudadanos y la renuncia a toda certeza de derecho.

En consecuencia, el Estado de seguridad no atañe ni al Estado de derecho, tal como se lo concibe tradicionalmente, ni a aquello que Michel Foucault llamaba las

\footnotetext{
7 “La primera acción de Hitler, después de su nombramiento, fue proclamar un estado de excepción, que jamás fue revocado...”.
} 
"sociedades disciplinarias". Mientras que en el modelo hobbesiano, el Estado pone fin al miedo, en el Estado de seguridad este esquema se invierte: el Estado se funda en el miedo y debe, a toda costa, mantenerlo, pues extrae de él su función esencial y su legitimidad. "El Estado se confunde con las FF. AA., la política aparece como guerra, los adversarios como enemigos" (CALVEIRO, 1998, p. 30).

\section{La politicidad del hombre y el lenguaje}

La tradición ético-política occidental se funda sobre dos principios: la legalidad (las instituciones, las leyes y las modalidades de ejercicio del poder), y la legitimidad (el principio que funda el poder).

En este sentido, y tal como Agamben lo sostiene en su última obra El misterio del mal (2013), las instituciones de una sociedad permanecen vivas sólo si ambos principios están presentes, pero agrega inmediatamente para evitar posibles malinterpretaciones: "No se trata de que la legitimidad sea un principio sustancial jerárquicamente superior, del que la legalidad jurídico-política sólo sería un epifenómeno o un efecto. [...] si, como ha sucedido en los Estados totalitarios del siglo $\mathrm{XX}$, la legitimidad pretende prescindir de la legalidad, entonces, la máquina política gira en el vacío con resultados frecuentemente letales; o, por otra parte, como ha sucedido en las democracias modernas, si el principio legitimante de la soberanía popular se reduce al momento electoral y se resuelve en reglas procedimentales jurídicamente prefijadas, la legitimidad corre el riesgo de desaparecer en la legalidad y la máquina política igualmente se paraliza" (AGAMBEN, 2013, p. 57).

Para el filósofo italiano, el intento de la Modernidad de hacer coincidir la legalidad y la legitimidad, buscando asegurar a través del derecho positivo la legitimidad de un poder, es insuficiente. Si bien en El misterio del mal Agamben no nos dice nada acerca de cuál sería ese elemento que permitiría articular ambas dimensiones, legitimidad y legalidad, no obstante este silencio, Edgardo Castro (2013) teniendo en cuenta otras obras del autor, sitúa este eje en lo que define la politicidad propia del hombre, es decir, en el lenguaje. Con ello, se supera la definición aristotélica del hombre como animal político, ya que para el filósofo griego las hormigas y las abejas al ser gregarios también son insectos políticos pues persiguen una obra común mediante la división de tareas, ofreciendo un modelo de organización política en el que no se plantean las cuestiones de la legitimidad y de la legalidad.

Valiéndonos de la hipótesis de Castro, podemos llevar esta idea a la dictadura de 1976. Castro (2013, p. 17) afirma: "Si la politicidad del hombre pasa por el lenguaje, cuando se pierde ese nexo entre política y lenguaje, la máquina deja de funcionar. Es el triunfo de la dimensión zoológica de la política. A veces, porque la legitimidad ha absorbido la legalidad, como sucede en las formas totalitarias a través de la subordinación del Estado a la voluntad de su conductor o Führer. Otras, al contrario, porque la legitimidad se ha disuelto en la legalidad meramente procedimental. Pero siempre, porque las palabras, vaciadas de su semántica y de su función argumentativa, se han convertido finalmente en imágenes-fetiche".

Bajo la dictadura de 1976, el silencio se impuso sobre la palabra ${ }^{8}$, a la vez que el lenguaje humano fue degradado a niveles nunca antes conocidos. Por ello, el poder dictatorial no sólo fue ilegítimo porque se impuso luego de un golpe militar que derrocó

\footnotetext{
${ }^{8}$ De acuerdo con el comunicado № 19 "la Junta de Comandantes Generales ha resuelto que sea reprimido con la pena de reclusión por tiempo indeterminado el que por cualquier medio difundiere, divulgare o propagare comunicados o imágenes provenientes o atribuidas a asociaciones ilícitas o personas o grupos notoriamente dedicados a actividades subversivas o al terrorismo...".
} 
a un gobierno democrático, aunque intentara crear su propia legalidad, sino porque al obturar la palabra, triunfó el aspecto exclusivamente animal de la política. El animal, al carecer de lenguaje discursivo, no le es posible argumentar acerca de lo justo o lo injusto, de lo bueno y lo malo, dice Aristóteles en la Política. La categoría de biopolítica ha puesto en primer plano la estrecha relación que existe entre la política y la vida biológica, de ahí su innegable centralidad en el pensamiento político contemporáneo.

\section{Bestialidad y soberanía política9}

Diversas figuras encarnan la excepción, sea la del soberano como centro de la decisión y el poder, sean las de la persecución. En el seminario La bestia y el soberano (2010), Derrida analiza la compleja relación existente entre estas dos figuras, explorando la lógica de los vínculos que unen la animalidad con la soberanía política, así como la analogía constante que puede tenderse entre ellas.

Las figuras del soberano y la bestia indican la excepción: están fuera-de-la-ley; uno por hallarse "encima" o por ser la ley misma, y la otra por estar "debajo" de la ley y transgredirla. El carácter de exterioridad respecto de la ley no solo involucra en su lógica a los que se suponían opuestos, sino que permite dar cuenta del carácter que gobierna ese estar fuera-de-la-ley, señalando la dinámica misma de la economía de la violencia que puede transparentarse en la distinción en dos polos de lo que es externo, donde solo uno de ellos -la soberanía- gobierna sobre el otro (TORRANO; LORIO, 2012).

La figura zoopolítica del lobo aúna en sí soberanía y bestialidad. En este sentido, Derrida vincula a la soberanía con la posición de "cierto poder de dictar, de hacer pero asimismo de suspender la ley; es el derecho excepcional de situarse por encima del derecho, el derecho al no-derecho" (DERRIDA, 2010, p. 38 y ss.). Bajo esta situación, el soberano corre dos riesgos: situarse por encima de lo humano y dirigirse hacia la omnipotencia divina (fundamento de la soberanía en su origen sagrado y teológico) o parecerse a "la bestia más brutal que ya no respeta, desprecia la ley, se sitúa fuera de la ley, a distancia de la ley” (Ibidem, p. 36). Este último caso es el que puede asociarse al tipo y calidad de soberanía instalada a partir de 1976. Se inaugura una etapa política que incluye la ferocidad del soberano.

El estar fuera-de-la-ley es lo que tienen en común el soberano y la bestia. Uno por exceso y el otro por defecto se relacionan con la ley desde la extranjeridad: "en el no-respeto de la ley absoluta, de la ley absoluta que ellos establecen o que son, pero que no tienen por qué respetar" (Ibidem, p. 366).

Como expresa Derrida (2010, p. 36), estar fuera-de-la-ley alude a esa condición en la que la ley no aparece o se viola: señala tanto a la bestialidad como al criminal. De modo que entre el soberano, el criminal y la bestia se puede descubrir una inquietante complicidad, una cuasi-coincidencia que insinúa "por debajo de los rasgos del soberano, el rostro de la bestia; o, inversamente, [...] sería como si transparentara, a través de la jeta de la bestia indomable, una figura del soberano" (Ibidem, p. 37).

\footnotetext{
${ }^{9}$ La animalización de la política es una de las líneas directrices seguidas por Derrida. El filósofo repasa algunas de las figuras zoológicas que visten el discurso político como la paloma, símbolo de la paz, el lobo, metáfora del estado de guerra hobbesiano, la astucia del zorro y la fuerza del león del príncipe de Maquiavelo, el hombre-lobo en la descripción que Rousseau hace de sí, hasta el rasgo compartido por bestias y soberano al situarse ambos fuera-de-la-ley: las primeras porque desconocen el significado normativo que impone la prescripción y el segundo porque tiene el derecho de suspender el derecho, de declarar el estado de excepción, como señala el jurista Schmitt.
} 
La bestia indomable derridenana nos remite al animal a partir del cual se ha descrito el comportamiento del hombre, cuya centralidad en la filosofía política moderna es indiscutible: el lobo. Aunque también alude al Leviatán, el monstruo bíblico. Tanto el momento previo al Estado como el Estado mismo están representados por figuras no humanas, a través de analogías con lo fuera-de-la-ley: el lobo, el Leviatán y Dios. Por ello para describir el Estado moderno, Hobbes recurre a la fórmula de Bacon Verulamio, según la cual el hombre es para el hombre un dios ("homo homini deus"), mientras que en el estado de naturaleza el hombre es para el hombre un lobo (“homo humini lupus") (HOBBES, 2004, p. 25).

El licántropo es la figura del que ha sido desterrado/banido de la comunidad, el hombre sin paz, el que literalmente es arrojado fuera de los márgenes de la comunidad de los hombres. La vida del excluido, como la del hombre sagrado, no es una pura naturaleza, sino que es una vida que permanece en un "no-lugar" entre la naturaleza y la ciudad, entre la physis y el nomos, sin pertenecer, paradójicamente, a ninguno de ellos. El hombre lobo señala "una zona de indistinción entre lo humano y lo animal, licántropo, hombre que se transforma en lobo y lobo que se convierte en hombre: es decir banido, homo sacer" (AGAMBEN, 2003, p. 137). Sin embargo, no se trata de una exclusión pura, expresa Agamben, sino de una exclusión inclusiva. En consecuencia, el estado de naturaleza al que se refiere Hobbes no es un estado natural que se abandona, sino que amenaza constantemente dentro del ordenamiento jurídico. No se trata tanto de la guerra de todos contra todos sino de una condición en la que cada uno es para otro hombre lobo, en la terminología derrideana. En consecuencia, el lobo no habita exclusivamente el estado de naturaleza, como una instancia prejurídica, y el hombre la ciudad, como instancia política. Ambos están presentes indistintamente: el estado de naturaleza sobrevive en el Estado. El fundamento del poder soberano no se encuentra en la libre cesión por parte de los súbditos de su derecho natural, sino en la conservación por parte del soberano de su derecho natural de hacer cualquier cosa a cualquiera, que se presenta como el derecho a castigar. En este sentido, para el filósofo italiano la violencia soberana no se funda sobre un pacto, sino en la exclusión inclusiva de la nuda vida en el Estado, de modo que, en la persona del soberano, el hombre lobo para el hombre habita en la ciudad (AGAMBEN, 2003, p. 138-139).

La lupificación del hombre y la hominización del lobo dan cuenta del estado de excepción que, mientras dura, disuelve a la ciudad y lleva a los hombres a morar en una zona de indistinción con las fieras. En consecuencia, el estado de naturaleza es el estado de excepción, en el que la ciudad aparece solo por instantes. El corrimiento del velo que hace visible esta indistinción originaria, se produce con total transparencia bajo los designios de un golpe de Estado como el ocurrido en Argentina en 1976. En efecto, los "subversivos" habitan en una zona hostil, perseguidos por las fieras que ahora, sin mediaciones, se han hecho con el poder del Estado (DERRIDA, 2010, p. 46).

\section{La "suspensión" de la vida}

Es debido al miedo que reina en el estado de naturaleza que los hombres, a través del contrato, crean el Estado, según Hobbes. Pero para mantener las condiciones de paz en el Estado es necesaria una instancia decisoria que imponga el orden. El miedo es la explicación de un Estado omnipotente y lo que le confiere legitimidad. No obstante, el Estado no elimina el miedo, sino que lo estabiliza, lo hace "motor y garantía de su propio funcionamiento" (ESPOSITO, 2005, p. 61). En otras palabras, el miedo del estado de naturaleza es combatido con un miedo de mayor intensidad. Según Trías, el miedo lleva a construir "un instrumento que es, de hecho y de derecho, instrumento de 
terror. El canje es miedo por terror" (TRÍAS, 2005, p. 42). En el caso argentino, a "aceptarlo".

El deslizamiento de un Estado público hacia un Estado clandestino/terrorista, como diría Duhalde (1983), y cuya transición es el estado de excepción, es una posibilidad siempre presente en la propia estructura del Estado moderno aun en períodos democráticos.

El estado de excepción implica, asimismo, la instauración de una "guerra civil legal" que permite la eliminación física de cualquier adversario político declarado, y de cualquier otro ciudadano no integrable al sistema político. En este sentido, la vida queda suspendida y depende de una "decisión".

En consecuencia, vida y muerte no son procesos naturales inmediatos, sino que están mediados por una de las figuras de la excepción, el "golpista" en el caso argentino, que marca y decide desde sí mismo el nuevo derecho. El derecho del nuevo soberano es siempre desequilibrado, puesto que el "derecho sobre la vida" se ejerce en el momento en que puede aniquilarla. En el poder soberano, la muerte tiene preeminencia sobre la vida.

Podemos afirmar siguiendo a Agamben (2005a, p. 89) que la nueva estructura inaugurada en 1976 posibilita espacios de excepción dentro de los cuales toda vida es vida desnuda, despojada de sus cualidades, motivo por el cual se identifica con la "sustancia biopolítica absoluta". La vida desnuda encarna la zona de indistinción entre una vida protegida y reconocida por un orden jurídico-político dado y la mera vida biológica. Se trata de una vida que ha quedado fuera de la ley y a merced del poder soberano, porque en el estado de excepción la ley no se aplica.

Es a partir de esta consideración que Agamben (2005a, p. 223) afirma que en los campos de concentración nazi el estado de excepción se convierte en regla. Así, "a un orden jurídico sin localización (el estado de excepción, en el que la ley se suspendía) corresponde ahora una localización sin orden jurídico (el campo de concentración, como espacio permanente de excepción)". En el campo, en tanto espacio de excepción, las vidas no son más que meras vidas, vidas sin ningún estatuto jurídico. Allí sus moradores han sido despojados de "cualquier condición política y reducidos íntegramente a nuda vida [...] en el que el poder no tiene frente a él más que pura vida biológica sin mediación alguna" (Agamben, 2001, p. 40). El campo es "el más absoluto espacio biopolítico que se haya realizado nunca" (Agamben, 2001:40), donde vida y norma entran en un umbral de indistinción. Vidas que no son ofrendables, ni siquiera son sacrificables. Son matables, nadie hace el duelo por ellas.

En el caso argentino, fuera de la estructura de mandos, la Junta Militar creó Grupos de Tareas y Centros Clandestinos de Detención (CCD). Esta cartografía registró la existencia de 610 campos de concentración en 11 de las 23 provincias argentinas durante los primeros meses de 1976, cifra que luego se estabilizó en 364 (CONADEP, 2006). En algunos casos, fueron dependencias que ya funcionaban como sitios de detención. En otros se inauguraron en locales civiles, dependencias policiales y asentamientos militares. Los CCD respondían a una doble conducción: a los denominados "grupos de tareas" conformados generalmente por efectivos de la fuerza al mando del establecimiento, y a los responsables de cada zona (CONADEP, 2006, p. 257).

La secuencia de los "operativos" llevados adelante por los Grupos de Tareas seguía un modus operandi relativamente estable. El primer paso requería la coordinación de distintas fuerzas represivas. Esto suponía pedir "luz verde" en la jurisdicción policial para poder actuar. Una vez declarada el área liberada se procedía al secuestro de la víctima, ya fuera en su domicilio personal, en la vía pública, en el 
lugar de trabajo o de estudio (CONADEP, 2006, p. 17-25). La víctima, entonces, era secuestrada, encapuchada e ingresada a un CCD. Allí, el rito iniciático era la tortura, tanto física como psicológica, bajo el argumento de obtener información lo más rápido posible, sin embargo, aquella se prolongaba, muchas veces, durante el período de cautiverio. Contra la convicción común de que los dictadores destruían la ley, la extendieron hasta incluir en ella aquello que la excede manifiestamente. El "campo de concentración" no es el lugar de la ley, pero tampoco es el de la mera arbitrariedad. Es más bien el espacio donde lo arbitrario se torna legal y la ley arbitraria.

\section{Corolario y clausura: la guerra de Malvinas}

La derrota de Malvinas eclipsaría las aspiraciones castrenses de perpetuarse en el poder.

La dictadura cívico-militar de 1976 y la guerra de Malvinas son dos caras del mismo fenómeno: despersonifica a la víctima que pasa a ser un mera vida desnuda, constituyendo uno de los ejemplos más terribles de "control biopolítico". Cuando ya las fronteras no son suficientes, el conflicto se desplaza hacia el exterior buscando la legitimidad que nunca se tuvo. "Malvinas" adquirió un carácter vergonzante pero también "menor" frente a las desapariciones y torturas sistemáticas y masivas fruto de la "guerra preventiva". Así, sus combatientes quedaron sometidos a una doble marginación: son los últimos entre las víctimas de la dictadura argentina.

Los exterminios o genocidios son considerados, generalmente, una anomalía histórica, especie de retroceso de la historia o paréntesis aberrante en su marcha de progreso continua. Este quiebre regresivo aunque puntual en el proceso civilizatorio, se creyó ajeno a la condición humana. Para Hannah Arendt (2002), contrariamente, los genocidios son su manifestación. También la guerra, en ese sentido, "es un fenómeno permanente que perdura en virtud de su plasticidad política" (ARENDT, 2002, p. 67). "La guerra de Malvinas no fue un anacronismo histórico -puede que sí en la 'puesta en escena' aeronaval y anfibia, un tanto obsoleta en el umbral de las guerras de los misileso un 'accidente' irracional, inexplicable y absurdo a finales del siglo XX. La guerra fue una decisión conscientemente tomada por sendos gobiernos que sabían que mandaban a una probable muerte a cientos de jóvenes", afirma María José Bruña Bragado (2012). Fue una estrategia de la "biopolítica" utilizada por dos estados, civilizados y bárbaros a la vez, para perpetuarse en el poder. La Inglaterra democrática y la Argentina dictatorial se encontraban en la cuerda floja, en una encrucijada de su historia y, por ello, recurrieron a la guerra para silenciar voces opositoras, críticas y desesperanzadas.

El fracaso del proyecto económico, el desprestigio del gobierno, la débil unidad de las FF.AA. y el despertar de la sociedad civil, son los elementos principales que rodean la aventura de Malvinas.

Con la operación del 2 de abril se especulaba obtener un efecto cohesivo en el orden interno: tanto en el frente militar como en el campo de la sociedad civil. Con ello el régimen militar quedaría legitimado e "inmortalizado" tras un acuerdo cívico-militar.

\section{Conclusiones}

El golpe de Estado precedió al Estado terrorista. El "estado de excepción" se "legitimó" por una percepción de amenaza al estado de derecho o a la Constitución Nacional. Ese estado operó en un espacio vacío de derecho, en el cual todas las determinaciones jurídicas fueron desactivadas. En este sentido, "es ese momento del derecho en el que se suspende el derecho, precisamente para garantizar su continuidad e 
inclusive su existencia. O también: la forma legal de aquello que no puede tener forma legal, porque es incluido en la legalidad a través de su exclusión", afirma Agamben (2005a). El golpe se justificó en un supuesto "vacío de poder", responsabilizándose por ello a las "rígidas estructuras políticas y económicas anacrónicas". Las FF.AA. se han pensado a sí mismas como garantes de los principios, valores y normas constitutivas de la Nación, de ahí que se reclamen una vez más en 1976 tutores de la integridad del Estado (ROUQUIÉ, 1982) justificando así su acción golpista; y lo hicieron en nombre de una democracia "pura" que se ha corrompido, apelando a principios republicanos y a una "esencia nacional" ahistórica transfigurada por el conflicto social al cual no reconocen como legítimo de toda sociedad históricamente constituida.

El terrorismo de Estado instituyó como metodología la desaparición. Wolfgang Sofsky, citado por Giorgio Agamben (2005b, p. 58) afirma: "En el acto de matar, el poder se suprime a sí mismo. Por el contrario, al someter a sus víctimas al hambre y la degradación, gana tiempo, lo que le permite fundar un tercer reino entre la vida y la muerte". De eso se trata la desaparición. Convertido en un código, despojado de su nombre en vida, el desaparecido no estaba "ni vivo ni muerto" ${ }^{\text {. }}$. El desaparecido como un espectro delineó la "muerte argentina".

Según Agamben, el campo de concentración nazi es la culminación de este proceso en el que la biopolítica se realiza como tanatopolítica.

La Junta Militar festejó en 1979 la "Conquista del Desierto". Ambos hechos, la Conquista y la derrota de la "subversión apátrida", son simétricos y paralelos. Ser "apátrida" es ser lo Otro de la patria. Lo Otro es nada, por ende, la "subversión apátrida" no pertenece a la condición humana. Los dictadores del '76 evocaban a Roca para revestir con el sentido de una refundación de la Nación amenazada, una faena de exterminio (VEZZETTI, 2002). La gran "Campaña al Desierto" de 1879 fue un triunfo definitivo para los blancos. Julio A. Roca penetró profundamente en ese "Desierto" poblado de indios-, destruyendo sus asentamientos y, de un solo impulso, llevó la frontera hasta el Río Negro en la Patagonia argentina. En pocos meses, el fusil Remington se impuso sobre lanzas, boleadoras y flechas. Unas 1500 leguas de tierra fueron incorporadas a la provincia. Esta tierra no fue entregada a colonos, sino a grandes propietarios en enormes extensiones. La tierra de la Provincia de Buenos Aires quedó en manos del patriciado, unas pocas familias, las de siempre.

El paralelismo es muy significativo. Fuerzas inmensamente poderosas enfrentaron y aniquilaron a grupos en retirada, y subterráneamente la tortura y la desaparición completaban el exterminio. Como 100 años antes, grupos económicos poderosos fueron beneficiados con el nuevo patrón de acumulación impuesto (BASUALDO, 2006).

Tomando términos de Esposito nuevamente, communitas remite a la idea de lo común, lo no propio. Se compone de cum, como aquello que vincula, y munus, en tanto don obligatorio entre los miembros de la comunidad. Inversamente, el estado que analizamos se inmuniza, pues se sustrae de muchas de sus obligaciones. En este sentido, "lo inmune" es lo opuesto a "lo común"; inmune es aquél que es dispensado de la carga del munus, o sea, se sustrae a las obligaciones. Por otro lado, la relación sujeto/comunidad se articula en torno a la centralidad de la propiedad (ESPOSITO, 2005; 2010). El régimen militar inaugurado en 1976 puede ser visto como una de las modalidades paradigmáticas de lo inmune, como defensa de lo propio y lo privado en contraposición a lo común y no-propio.

10 "Le diré que frente al desaparecido en tanto esté como tal, es una incógnita, mientras sea desaparecido no puede tener tratamiento especial, porque no tiene entidad. No está muerto ni vivo...está desaparecido". (Declaraciones de Videla en conferencia de prensa dada el 14/12/1979). 
Asimismo, el supuesto terrorista fue considerado nuda vida, homo sacer, es decir, alguien que puede ser asesinado impunemente. Al igual que en la "Campaña del Desierto", los nuevos exterminadores se enfrentaban a "nadie", a un "no-ser", a alguien carente de humanidad como los indios de la Patagonia. La noción de biopoder -la vida biológicamente considerada, la nuda vida- "en su doble faz, como poder sobre la vida y como poder sobre la muerte", se muestra con toda crudeza en la acción del Estado terrorista argentino, destinado a intervenir, una vez más, frente al caos y los fantasmas de la anarquía en un proyecto de salvación nacional.

A la guerra no convencional -"preventiva" en términos biopolíticos- le debía suceder una etapa de estabilidad a partir de una convergencia "definitiva" entre civiles y militares. La supervivencia de la "Nación" misma estaba en juego. Por ello, hubo una voluntad expresa de destruir la identidad de los sectores populares que se expresaba en el peronismo. Todo vestigio de populismo debía ser desterrado de la faz de la Argentina (BASUALDO, 2006, p. 30). Las FF.AA. no operaban representando intereses sectoriales sino que eran "los fundadores" de una Argentina que el accionar de la subversión y de los populistas habían desvirtuado.

El golpe abrió las puertas a un cambio drástico en la distribución del poder social, sentándose las bases para el empobrecimiento de sectores medios y populares en beneficio de los grandes grupos económicos. No sólo se profundizaron las asimetrías. Las expectativas con que habían crecido social y culturalmente los argentinos se hicieron pedazos.

Para que haya cuerpos productivos tiene que haber cuerpos sometidos. Todo sometimiento económico conlleva un sometimiento político que lo posibilita. Al analizar la historia reciente, queda a la vista que la implantación del neoliberalismo económico solo fue posible mediante la dominación de esos cuerpos. Llegados a este punto es necesario resaltar las marcas que el poder dejó no sólo sobre los cuerpos de los detenidos-desaparecidos, sino también sobre la sociedad en su conjunto. El dominio ejercido sobre esos cuerpos y la violencia del poder disciplinario no son directos. La "docilización" es mucho más sutil. Con los dispositivos disciplinarios funcionando mediante castigos y recompensas, se inmovilizó a buena parte de la sociedad. Ese es el gran éxito que consiguió la dictadura: someter a la sociedad por el miedo. El vigilar resultó tan efectivo como el castigar. Asimismo, la lucha contra el "subversivo" permitió confundir excepción con normalidad, ante el "convencimiento" que peligraba la supervivencia misma de la Nación argentina.

La aceptación de los valores del "ser nacional", homogéneo y resistente a cualquier tipo de cambio, estuvo marcada por la inoculación del miedo; el terrorismo de Estado penetró todos los ámbitos sociales. De manera paralela al funcionamiento de los instrumentos coercitivos, la "política del miedo" se ejercía como una violencia simbólica que paralizaba a aquellos sectores sociales no cooptados a la vez que se recuperaban representaciones conservadoras que habían sido puestas en tela de juicio a partir de los '60. Sobre esta base, los métodos propagandísticos tuvieron efectos similares a los de la Alemania nazi, es decir, la recepción acrítica de los mensajes y la consecuente conducta social en los términos planificados por la Junta Militar. Como bien se manifiesta en "Los rostros del biopoder" (SCIPIONI et al, 2008), "existe un punto evidente de continuidad semántica entre los estados nazi y el argentino de 19761983 en relación a la apología de los valores occidentales clásicos; aparece una muletilla a la que se acudía mucho por entonces, 'la defensa de la civilización occidental y cristiana', casi una réplica del paradigmático slogan 'por la defensa de la civilización cristiana' creado por Joseph Goebbels durante el nazismo". 
Apenas terminada la guerra de Malvinas, comenzaron a descubrirse las huellas más visibles de la represión: enterramientos, lugares de detención y tortura, testimonios de sobrevivientes.

Por su parte, el "legado" económico dejó a la sociedad y a las autoridades entrantes un endeudamiento masivo, un aparato productivo deteriorado y un pronunciado proceso de desindustrialización.

\section{Referências}

AGAMBEN, G. “¿Qué es un campo?”. En Medios sin fin. Notas sobre la política. Valencia: Pre-Textos, 2001.

Homo sacer I. El poder soberano y la nuda vida. Valencia: Pre-Textos, 2003.

$2005 \mathrm{a}$.

Estado de excepción. Homo sacer, II, I. Buenos Aires: Adriana Hidalgo Editora,

Lo que queda de Auschwitz. El archivo y el testigo. Homo sacer III. Valencia: PreTextos, 2005b.

. El misterio del mal. Benedicto XVI y el fin de los tiempos. Buenos Aires: Adriana Hidalgo Editora, 2013.

ARENDT, H. Los orígenes del totalitarismo. Madrid: Gallimard, 2002.

ASPIAZU, D.; BASUALDO, E.; KHAVISSE, M. El nuevo poder económico en la Argentina de los ochenta. Buenos Aires: Legasa, 1986.

BASUALDO, E. Sistema político y modelo de acumulación en la Argentina. Buenos Aires: UNQ, 2006.

BENJAMIN, W. Para una crítica de la violencia y otros ensayos. Madrid: Taurus, 1991.

BRUÑA BRAGADO, M. J. Ruinas del imaginario nacional argentino: contar Malvinas. Salamanca: Universidad de Salamanca, 2012.

CALVEIRO, P. Poder y desaparición. Buenos Aires: Colihue, 1998.

Política y/o violencia. Una aproximación a la guerrilla de los años $\mathbf{7 0}$. Buenos

Aires: Norma, 2005.

CASTRO, E. "Historia del misterio del mal". Revista Ñ, 2013, p.15.

DERRIDA, J. Espectros de Marx. El estado de la deuda, el trabajo de duelo y la nueva internacional. Madrid: Trotta, 1995.

Seminario La bestia y el soberano. Volumen I (2001-2002). Buenos Aires: Manantial, 2010.

DOCUMENTOS DEL PROCESO DE REORGANIZACIÓN NACIONAL. Documentos Básicos y Bases Políticas de las Fuerzas Armadas para el Proceso de Reorganización Nacional (recopiladas en 1980), 24 de marzo de 1976; El Ejército de hoy, 17 de agosto de 1976; Documento Reservado del Ejército Argentino, 23 de agosto de 1976; Marxismo y subversión. Ámbito laboral, Estado Mayor General del Ejército; Instrucción para operaciones de seguridad del Ejército, 1977; Manual RE-9-51; La verdad sobre el marxismo-leninismo, Círculo de la Fuerza Aérea, 1977: Observaciones y Comentarios Críticos del Gobierno Argentino al Informe de la CIDH sobre la situación de los derechos humanos en Argentina, Círculo Militar, abril de 1980; Documento final de la Junta Militar sobre la guerra contra la subversión y el terrorismo, abril de 1983. ((www.ruinasdigitales.com.ar mayo/2010).

DUHALDE, E., L. El Estado terrorista argentino. España: Argos-Vergara, 1983.

ESPOSITO, R. Communitas. Origen y destino de la comunidad. Buenos Aires: Amorrortu, 2005.

Immunitas. Protección y negación de la vida. Buenos Aires: Amorrortu, 2010.

FEINMANN, J. P. Escritos de José Pablo Feinmann sobre la dictadura de 1976. Em: www.salvajespalabras.com (febrero 2015).

FRANCO, M. Un enemigo para la nación. Orden interno, violencia y "subversión", 1973 1976. Buenos Aires: Fondo de Cultura Económica, 2012.

INFORME DE LA COMISION NACIONAL SOBRE LA DESAPARICION DE PERSONAS (CONADEP). Buenos Aires: EUDEBA, 2006. 
KAUFMAN, A. "Notas sobre desaparecidos". Revista Pensamiento de los Confines. n. 4, Buenos Aires, 1997, p.27-35.

LVOVICH, D. A propósito de Marina Franco. Un enemigo para la nación. Orden interno, violencia y "subversión”, 1973 - 1976. Buenos Aires: FCE, 2012.

MARRAMAO, G. Contra el poder. Buenos Aires: FCE, 2013.

MICIELI, C. "Protección y negación de la vida: la tanatopolítica bajo el nazismo". Páginas de Filosofía. Neuquén, 2010.

NOVARO, M.; PALERMO, V. La dictadura militar 1976/1983. Del golpe de Estado a la restauración democrática. Buenos Aires: Paidós, 2003.

QUIROGA, H. El tiempo del "Proceso". Conflictos y coincidencias entre políticos y militares 1976-1983. Santa Fe: Homo Sapiens, 2004.

REATO, C. Disposición Final. La confesión de Videla sobre los desaparecidos. Buenos Aires: Sudamericana, 2012.

ROUQUIE, A. "Hegemonía militar, Estado y dominación social". In: ROUQUIÉ, A. (comp.). Argentina hoy. Buenos Aires: Siglo XXI, 1982.

SALAS, E. "Cultura popular en la primera etapa de la resistencia peronista (1955-1958)", Revista Secuencia, enero de 1994.

SCIPIONI, L.; SALAZAR, M.; RIVERO LEGUIZAMON, J. P. "Los rostros del biopoder". Jornadas de Cuerpo y Cultura. Universidad Nacional de La Plata, 2008.

SCHMITT, C. Teología política. Buenos Aires: Editorial Struhart \& Cía, 1998.

El Leviathan en la teoría del Estado de Thomas Hobbes. Granada: Editorial Comares, 2004.

SCHVARZER, J. La política económica de Martínez de Hoz. Buenos Aires: Hyspamérica, 1987.

TORRANO, A.; LORIO, N. "Economía de la violencia y figuras de la excepción. Soberanía y biopolítica". Revista Pleyade, n. 9, CAIP (enero-junio 2012), p. 101-118.

TRIAS, E. La política y su sombra. Barcelona: Editorial Anagrama, 2005.

VERGALITO, E. "¿Ricoeur vs. Derrida?: hacia una aproximación entre hermenéutica y deconstrucción". El pensadero. Revista de Filosofía, n. 1, Buenos Aires (junio 2005).

VEZZETTI, H. Pasado y Presente. Guerra, dictadura y sociedad en la Argentina. Buenos Aires: Siglo XXI Editores, 2002.

VILLARREAL, J. Dictadura y democracia (1976-2001). Buenos Aires: Sudamericana, 1985. 